\title{
ИСТОРИЗМ
}

\author{
Ю.Ю. Гордова
}

\section{АРХЕОЛОГИЧЕСКИЕ НАХОДКИ РЯЗАНСКОЙ ЗЕМЛИ КАК ИСТОЧНИКИ ДРЕВНЕРУССКОЙ АНТРОПОНИМИИ}

Аннотация. Предметом исследования являются личные имена, встречающиеся в надписях на бытовых предметах, которые были обнаружены при археологических раскопках на территории древнего Рязанского княжества. На рыбацком грузиле, пряслице и корчаге для вина IX-X, XII-XIII вв. начертаны имена Ерем[а], Молодило, Добрило, Богунка. В статье анализируются состав, характер, тип имён людей незнатных сословий и особенности употребления этих имён в роли подписи на предметах домашнего обихода. Несмотря на очевидную научную ценность, надписи с именами на ископаемой домашней утвари, игрушках и прочих вещах бытового использования пока остаются вне поля зрения лингвистов, а сама тема археологических находок (перечисленных выше) как источников антропонимов ещё не получила должного освещения в трудах учёныхономатологов.

При исследовании имён используется структурный и типологический методы. Антропонимы рассматриваются в региональном (как принадлежащие одной территории) и в ономастическом (как принадлежащие одному ономастическому классу антропонимов и одному полю - древнерусские имена жителей Рязанского вел. княжества) аспектах.

В ходе исследования эпиграфических находок подтверждено, что личное имя играло определяющую роль в древнерусский период. Среди некняжеских сословий ещё до татаро-монгольского нашествия бытовали и исконные русские, и христианские имена. Использование в качестве подписи народных форм имён свидетельствует об отсутствии в этот период такого свойства антропонимов, как формулярность. Представленные в статье материалы доказывают, что бытовые предметы, наряду с берестяными грамотами и летописями, могут служить важными источниками древнерусских антропонимов.

Ключевые слова: источники антропонимов, Рязанская земля, Древняя Русь, археологические находки, ономастика, личные имена, Антропонимия, региональная ономастика, древнерусская ономастика, лингвистика. Abstract. The subject of the research is the personal names inscribed on everyday items discovered in the Ryazan land. A number of everyday items with inscriptions containing forenames on them have been excavated in the territory of the ancient Duchy of Ryazan. The names, such as Erem[a], Molodilo, Dobrilo and Bogunka, are inscribed on a fishing plummet, a spindle whorl and a large earthenware wine pot; all of the above are dating back to the 9th-10th, 12th13th century. The antique signs help us discover composition of the names of those who are of humble origin as well as usage peculiarities of those names serving as a signature on everyday items. Despite obvious scientific value, inscriptions containing forenames found on excavated household items, toys and other everyday objects are still left out-of-sight of linguists and the aforesaid archeological discoveries have not been duly studied by onomatologists as sources of anthroponyms. In her research Gordova has used the structural and typological analysis methods. Anthroponyms are analyzed from the point of view of their regional (i.e. belonging to one region) and onomastic attribution (i.e. belonging to one onomastic class and field of anthroponyms, in particular, Old Russian names of people living in the ancient Duchy of Ryazan). The epigraphical findings confirm the fact that a forename played a defining role during the Old Russian period. Even before the Mongol conquest both native Russian and Christian names existed among the non-princely estates. The use of folk forms of forenames as inscriptions bears witness of the lack of such an anthroponymical quality as formulaicity. The presented items prove the fact that everyday objects, alongside with birchbark manuscripts and chronicles, can serve as an important source of the Old Russian anthroponyms.

Key words: anthroponymy, personal names/forenames, onomastics, archeological discoveries, Old Russia (Rus'), Ryazan land, sources of anthroponyms, regional onomastics, old Russian onomastics, linguistics. 
Ч резвычайный интерес для исследователя, занимающегося изучением древнерусской антропонимии, представляют отдельные археологические находки, а именно бытовые предметы: глиняные горшки, рыболовные снасти, инструменты, игрушки - с надписями, содержащими собственные имена. Как правило, такие находки носят единичный характер. При этом они поддаются более или менее точной датировке, а потому представляют особую ценность для ономастического исследования: древность найденного в земле бытового предмета говорит и о древности начертанного на нём имени, а если имя не зафиксировано в русских памятниках письменности, ценность источника ещё более возрастает. Несмотря на очевидную научную ценность, надписи с именами на ископаемой домашней утвари, игрушках и прочих вещах бытового использования пока остаются вне поля зрения лингвистов, а сама тема археологических находок (перечисленных выше) как источников антропонимов ещё не получила должного освещения в трудах учёныхономатологов.

Несколько десятков эпиграфических находок, в том числе и фрагмент единственной (на 2016 г.) берестяной грамоты обнаружены при археологических раскопках в Рязанской области. Область является исторической территорией Рязанского вел. княжества, одного из княжеств Древней Руси, сохранявшего свою самостоятельность с XII по XVI вв. Три надписи на этих находках содержат собственные имена. Эти имена никогда не были предметом детального изучения языковедов. Они никогда не рассматривались ни в региональном (как принадлежащие одной территории), ни в ономастическом (как принадлежащие одному ономастическому классу антропонимов и одному полю древнерусские имена жителей Рязанского вел. княжества) аспекте. Специальному - археологическому и палеографическому - изучению были подвергнуты лишь сами предметы и надписи на них. Результаты изучения представлены в статьях археологов и историков $[1 ; 6 ; 10]$. Введённые в научный оборот в данных статьях палеографические находки рассматриваются нами как источники новой информации, представляющей интерес для истории языка и ономастики.

1) Надпись «ерем...» (конец слова отсутствует) на фрагменте керамического рыбацкого грузила. Грузило обнаружено в культурном слое так называемого Дураковского комплекса поселений, датируемого IX-X, XII-XIII вв. Точная датировка самой находки не установлена.

Надпись выполнена чётким профессиональным почерком, по палеографическим приметам относит- ся к домонгольскому времени [10, с. 271]. Вероятно, она фиксирует имя человека, который изготовил данное грузило и пользуется им, Еремеи (Еремии), или сокращенный вариант этого имени Ерема.

Имя на бытовом предмете интересно прежде всего тем, что оно представляет собой форму христианского имени Иеремии, восходящего к древнееврейскому источнику [11, с. $103,104,116 ; 12$, с. 183]. Надпись подтверждает, что христианские имена уже использовались населением Рязанской земли в ранний древнерусский период. В числе находок Дураковского поселения есть предметы, непосредственно связанные с христианской культурой: каменные наперстные кресты, перстни с изображениями креста $[10$, с. 271]. Всё это говорит об известной степени религиозности населения данного района (в этот период его составляли представители вятичей и северян), хотя считается, что христианство в Среднем Поочье утвердилось относительно поздно.

Начальная часть имени, сохранившаяся на фрагменте, свидетельствует о том, что исходное имя уже претерпело значительные перестройки в соответствии с фонетической системой древнерусского языка и представляет собой народную форму церковного имени.

К сожалению, недостающий фрагмент грузила не позволяет увидеть конечную часть антропонима т.е. собственно окончание имени, которое могло бы рассказать о традициях личной подписи в древнерусское время и ответить на вопрос: какой - полный или сокращённый - вариант своего имени человек при этом использовал? Тем не менее, надпись дополняет наше представление о составе имён населения Рязанской земли в период до татаро-монгольского нашествия. Эти сведения особенно важны потому, что в ранних памятниках письменности имена простых людей почти не упоминаются.

2) Надпись «молодило» на пряслице, обнаруженном при раскопках на территории археологического памятника «Старая Рязань» [6, с. 212].

Пряслице (др.-р. пряслень) - грузик из глины, кости или камня круглой формы, насаживаемый на веретено для придания ему устойчивости и равномерности вращения. Пряслица использовали женщины при прядении. Однако поскольку в данном случае на предмете начертано мужское имя, находка трактуется как небольшой подарок мужчины, причём подразумевается, что и мужчина, и женщина были грамотными [6, с. 212]. Допустимо также, что имя - знак владельца, в пользу этого говорит характер надписи на втором обнаруженном в том же месте пряслице «княжее», а также замечание археологов, касающееся женских украшений, найденных на территории Старой Рязани: «Клады Батыева времени содержат, преимущественно, женские украшения. Однако, судя 


\section{Филология: научные исследования 1(21) • 2016}

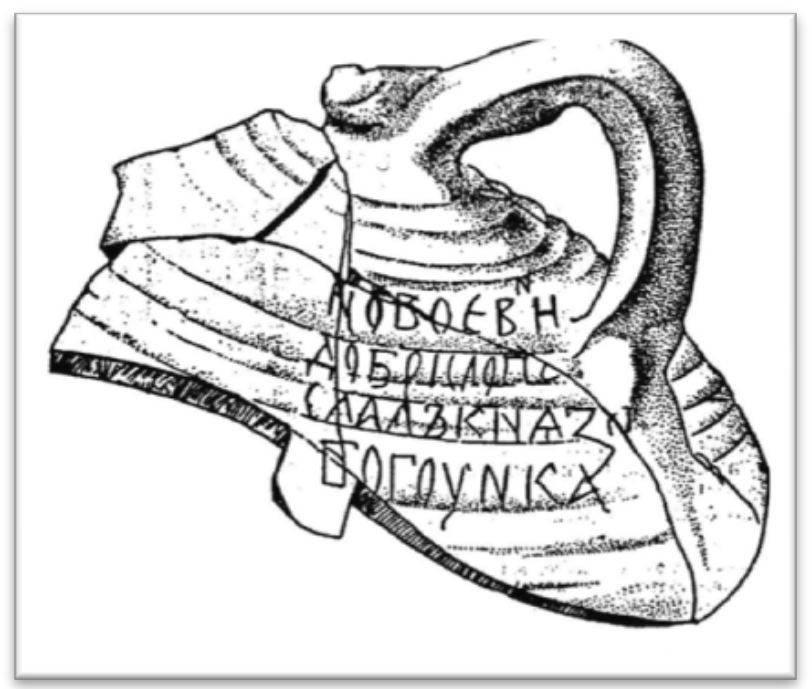

по нравам эпохи, это было ... имущество мужчиндворовладельцев» [1, с. 209].

Мужское имя Молодило не отмечено в известных списках древнерусских антропонимов, но, безусловно, оно относится к исконным русским именам и является одним из вариантов имени с корнем Молод- («молодой»). Полногласное сочетание -оло- выдает восточнославянский характер антропонима, ср. болг. Младе́н [11, с. 160]. Находка в Старой Рязани пряслица в надписью подтверждает известность в древнерусское время имени с корнем Молод- и употребительность антропонимического форманта -ило. Примечательно, что тот же корень мы находим в рязанской гидронимии - названиях рек бассейна Оки: Молоделка, Молодка [2, с. 63].

Пряслица с нанесёнными на них именами найдены и в других регионах России.

3) Надпись в четыре строки, содержащая собственные имена Добрило, Богунка, на корчаге с ручкой, обнаруженной в 1948 г. при раскопках на территории археологического памятника «Старая Рязань»; находка датируется XII-XIII вв. [6, с. 212-213].

Корчага - большой глиняный горшок, используемый в XII в. для хранения и измерения объёма вина. Обычно корчага вмещала два ведра вина, т.е. приблизительно 25 л.

Полный текст надписи: «новое $\mathrm{B}^{\mathrm{N}} \mathrm{H}$ добрило послалъ кнАzю богунка». Текст трактуют по-разному; затруднения вызывает, главным образом, объяснение слов «добрило» и «богунка». Первое рассматривают и как личное имя, и как наименование сорта вина, и как прилагательное, характеризующее качество вино; второе - как уменьшительную форму имени Богуслав или Богухвал, употребленную в именительном падеже, т.е. как имя того, кто послал вино. Один из предлагаемых переводов: «Новое вино доброе послал князю (человек по имени) Бо- гунка» [6, с. 212-213]. Всё же вряд ли можно видеть в слове «добрило» прилагательное: такое образование от корня добр- в древнерусском языке было невозможно. Лексема не встречается в ранних текстах и, как следствие, не отражена в современных академических словарях древнерусского языка [7; 9]. А вот образование имени собственного от этого корня возможно. Древнерусское имя Добрило известно. Его носил, в частности, автор так называемого Добрилова Евангелия, книги из библиотеки Ивана Грозного (памятник хранится в Российской государственной библиотеке). Евангелие было написано в 1164 г. дьяком Констянтином, в миру носившем имя Добрило: «В лето 6672 написаны быша книгы сия месяца августа в 6 день мною грешным рабом и дьяком Святых апостолов Констянтином, а мирьскы Добрило Семеоноу попови Святаго Иоана Предтеча» [4, с. 270].

Антропонимы с Добр- были широко употребительны в Древней Руси. Они образуют стройный ряд производных имен: Добромир, Доброслав, Добромысл (сложные имена); Добрило, Добрыня, Добрен, Добрин, Добрян (народные формы древнерусских имен). Такой же стройный ряд образует и формант -ило - традиционный аффикс древнерусской антропонимии. Он венчает и рассмотренное выше имя на пряслице (Молодило), и народные формы древнерусских имён (Добрило, Строило, Ярило), и народные формы календарных имён (Данило, Михаило и др.). Нельзя не отметить тот факт, что в Ярославской, Вологодской, Новгородской областях известны топонимы Добрилово (названия трёх деревень и одного села), которые, очевидно, имеют отантропонимическое происхождение.

Второе имя - Богунка - можно рассматривать как народную форму древнерусского Богун. Такое имя указано в «Словаре русских личных имён» А.В. Суперанской как вариант имени Богдан и сокращенная форма имён, начинающихся на Бог- (Богуслав, Богухвал, Боголюб и под.) [12, с. 130-131]. Богун может быть и прозвищным именем, связанным с наименованием растения багульник [3, с. 141]. Известны современные фамилии Богунко (Украина), Богунков (Украина, Россия), а в Гродненской области Белоруссии (где традиционны названия сельских поселений в форме мн. числа, образованные от антропонимов: Мохначи - от Мохнач, Марчуки - от Марчук и под.) - деревня Богунки.

Таким образом, оба слова в надписи на корчаге и «добрило», и «богунка» - могут быть истолкованы как антропонимы, однако в этом случае остаётся неясным смысл написанного: кто послал вино князю - Добрило или Богунка?

Нельзя не заметить, что на корчаге последнее слово - «богунка» - начертано более крупными буквами (см. Рис. 1). Возможно, автор надписи хотел вы- 
делить его как имя того, кто послал вино. Но как тогда рассматривать имя Добрило? Скорее всего, Добрило здесь не антропоним, а собственное имя другого вида - наименование сорта вина, причем наименование метафорическое: Добрило - «напиток, который делает добрым». Поскольку слово не отмечено в известных памятниках письменности, возможно, оно имело местное (ряз.) или профессиональное употребление (бытовало в среде виноделов).

Известно, что вино в Древней Руси делали из ягод и плодов, мёда или хмеля. В этой связи интересным представляется тот факт, что рядом с древней Рязанью находилось поселение Добрый Com, упоминаемое в летописях в 1207-1208 гг: «Пришедши же к Доброму Соту, хотел заутро перейти реку Проню» [5, с. 110]; в Лаврентьевской летописи текст с нетипичным названием села при редактировании ошибочно переосмыслен: «И бывшю ему у Добраго, въста и хотяше наутрия бродитися через Проню реку и поити к городу...» (осада Пронска в 1207 г. войском вел. кн. Всеволода Чермного) [5, c. 107]. Жители села занимались плодоводством и бортничеством, что и отражает топоним, в составе которого мы видим также и прилагательное с корнем добр-. Мёд и яблоки служили сырьём для производства местного вина, один из сортов которого, возможно, и назывался Добрило. В этом случае фраза, начертанная на корчаге, обретает вполне понятный смысл. Безусловно, предложенное объяснение - всего лишь гипотеза: лексема в такой форме и с таким значением не зафиксирована ни в «Словаре русских народных говоров» [8, с. 75-80], ни в известном словаре В. Даля [3, с. 410-412], нет возможности найти диалектизм и в рязанском областном словаре (ввиду отсутствия такового), а значит, слово могло быть утрачено.

В заключение отметим, что имя самого князя в надписи не указано, так как в этом не было необходимости: оно и так было хорошо известно всем живущим в данной местности (сосуд найден в Старой Рязани, где в XII - нач. XIII вВ., вплоть до сожжения города Батыем в 1237 г., находился княжеский стол).

Конечно, обнаруженные при раскопках бытовые предметы дают в руки исследователя не столь большое число древних имён, как, например, берестяные грамоты, которые являются богатейшим источником древнерусской антропонимии. Так, Новгородские грамоты XI-XV вв., содержащие частную переписку горожан, сообщают нам о жителях древнего Новгорода, носящих имена Грикша, Есиф, Онаний, Филип, Михаль, Бобр, Фалей, Борис, Потр, Микита, Онфим, Кощей, Федосья, Ностасия, Улиааница и мн. др. [13, с. 36-40].

Берестяные грамоты обнаружены также в Старой Руссе, Пскове, Смоленске. Однако этот вид ис- точника доступен не для всех регионов, так как для сохранения бересты нужна особая, богатая влагой почва, предохраняющая органические вещества от доступа воздуха и разложения. Изделия же из глины сохраняются в земле гораздо лучше, предметы домашнего обихода находят при раскопках в разных русских областях. Начертанные на них имена людей, живших в данной местности несколько столетий назад, представляют свой научный интерес.

Антропонимы, источниками которых стали археологические находки, обнаруженные на исторической территории Рязанского вел. княжества, подтверждают общие тенденции в именовании и функционировании имён на всей территории древнерусского мира, при этом позволяют акцентировать внимание исследователей на следующих моментах.

Если летописи дают нам представление в основном о системе княжеских имён, то надписи на бытовых предметах (грузилах, пряслицах, горшках) - о системе имён простых людей, о составе и особенностях которой в ранний период мы имеем весьма неясное представление. Напротив, имена князей в этих надписях, даже при их упоминании («княжее», «...послал князю...»), не указываются.

Во всех известных нам сегодня надписях зафиксированы только личные имена, что подтверждает положение о том, что в древнерусский период личное имя играло основную идентифицирующую роль. Среди некняжеских сословий в период до татаромонгольского нашествия бытовали и исконные русские, и христианские имена. И те, и другие использовались преимущественно в народных формах.

Указание своего имени на предметах материальной культуры являлось одной из культурных традиций древнерусского времени. Подпись могла быть и знаком мастера (например, клеймо на глиняной посуде), и знаком владельца данного предмета. Использование в качестве подписи народных форм имён свидетельствует об отсутствии в этот период такого свойства антропонимов, как формулярность - назначения выполнять функцию официального именования человека. О начале формирования этой функции у имён собственных говорят относящиеся к тому же времени подписи на произведениях древнерусского зодчества и иконописи, в которых употребляются уже и полные, в том числе и строгие канонические формы имён.

Таким образом, бытовые предметы, обнаруженные в ходе археологических раскопок, наряду с берестяными грамотами и летописями, могут быть источниками древнерусских антропонимов, причём источниками весьма своеобразными, а потому они обязательно должны попадать в поле зрения специалистов, изучающих имена как часть духовной культуры Древней Руси. 


\section{Филология: научные исследования 1(21) • 2016}

\section{Список литературы:}

1. Буланкина Е.В., Стрикалов И.Ю., Чернецов А.В. Клад 2005 г. из раскопок на Южном городище // Великое княжество Рязанское: историко-археологические исследования и материалы. М.: Памятники исторической мысли, 2005. С. $198-210$.

2. Гордова Ю.Ю. Топонимия Рязанской области (список географических названий). Часть І. Современная топонимия. Выпуск I. Территория бассейна реки Прони. Рязань: Рязань. Мip, 2010. 72 с.

3. Даль В.И. Толковый словарь живого великорусского языка: в IV тт. Т. I (а - з). М.: ОЛМА-ПРЕСС, 2004. 640 с.

4. Добрилово Евангелие / Российская государственная библиотека. Ф. 256. Рум. № 103.

5. «И были полки Ольговы...»: Свод летописных известий о Рязанском крае и сопредельных землях до 50-х гг. XVI в. / Сост. А.И. Цепков. М.: Прогресс-Культура, 1994. 512 с.

6. Медынцева А.А. Грамотность в повседневной жизни столицы Рязанского княжества // Великое княжество Рязанское: историко-археологические исследования и материалы. М.: Памятники исторической мысли, 2005. С. 211-221.

7. Словарь древнерусского языка (XI-XIV вв.): в 10 тт. / Под ред. Р.И. Аванесова. Т. 2 (възалкати - добродътсльникъ). М.: Русский язык, 1989. 494 с.

8. Словарь русских народных говоров / Под ред. Ф.П. Филина. Вып. 8 (дер - ерепениться). Л.: Наука, 1972.369 с.

9. Словарь русского языка XI-XVII вв. / Под ред. С.Г. Бархударова. Вып. 4 (г - дяфинъ). М.: Наука, 1977. 404 с.

10. Судаков В.В., Буланкин В.М. К вопросу о начальном этапе славянского расселения в Среднем Поочье // Русь в XI-XIV веках: взаимодействие Севера и Юга / Отв. ред. Н.А. Макаров, А.В. Чернецов; Ин-т археологии РАН. М.: Наука, 2005. C. 269-280.

11. Суперанская А.В. Современный словарь личных имен: Сравнение. Происхождение. Написание. М.: Айрис-пресс, 2005. $384 \mathrm{c}$.

12. Суперанская А.В. Словарь русских личных имен. М.: Эксмо, 2006. 544 с.

13. Янин В.Л. Я послал тебе бересту. М.: Изд-во МГУ, 1965. 192 с.

14. Зубенко Ю.С. Археологическая находка как специфический вид культурной ценности: проблема правового определения // Философия и культура. 2012. № 10. С. 70-75.

\section{References (transliterated):}

1. Bulankina E.V., Strikalov I.Yu., Chernetsov A.V. Klad 2005 g. iz raskopok na Yuzhnom gorodishche // Velikoe knyazhestvo Ryazanskoe: istoriko-arkheologicheskie issledovaniya i materialy. M.: Pamyatniki istoricheskoi mysli, 2005. S. 198-210.

2. Gordova Yu.Yu. Toponimiya Ryazanskoi oblasti (spisok geograficheskikh nazvanii). Chast' I. Sovremennaya toponimiya. Vypusk I. Territoriya basseina reki Proni. Ryazan': Ryazan'. Mir, 2010. 72 s.

3. Dal' V.I. Tolkovyi slovar' zhivogo velikorusskogo yazyka: v IV tt. T. I (a - z). M.: OLMA-PRESS, 2004. $640 \mathrm{s.}$

4. Dobrilovo Evangelie / Rossiiskaya gosudarstvennaya biblioteka. F. 256. Rum. № 103.

5. «I byli polki Ol'govy...»: Svod letopisnykh izvestii o Ryazanskom krae i sopredel'nykh zemlyakh do 50-kh gg. XVI v. / Sost. A.I. Tsepkov. M.: Progress-Kul'tura, 1994. 512 s.

6. Medyntseva A.A. Gramotnost'v povsednevnoi zhizni stolitsy Ryazanskogo knyazhestva // Velikoe knyazhestvo Ryazanskoe: istoriko-arkheologicheskie issledovaniya i materialy. M.: Pamyatniki istoricheskoi mysli, 2005. S. 211-221.

7. Slovar' drevnerusskogo yazyka (XI-XIV vv.): v 10 tt. / Pod red. R.I. Avanesova. T. 2 (v"zalkati - dobrod"tsl'nik"). M.: Russkii yazyk, 1989. $494 \mathrm{~s}$.

8. Slovar' russkikh narodnykh govorov / Pod red. F.P. Filina. Vyp. 8 (der - erepenit'sya). L.: Nauka, 1972. 369 s.

9. Slovar' russkogo yazyka XI-XVII vv. / Pod red. S.G. Barkhudarova. Vyp. 4 (g - dyafin"). M.: Nauka, 1977. 404 s.

10. Sudakov V.V., Bulankin V.M. K voprosu o nachal'nom etape slavyanskogo rasseleniya v Srednem Pooch'e // Rus' v XI-XIV vekakh: vzaimodeistvie Severa i Yuga / Otv. red. N.A. Makarov, A.V. Chernetsov; In-t arkheologii RAN. M.: Nauka, 2005. S. 269-280.

11. Superanskaya A.V. Sovremennyi slovar' lichnykh imen: Sravnenie. Proiskhozhdenie. Napisanie. M.: Airis-press, 2005.384 s.

12. Superanskaya A.V. Slovar' russkikh lichnykh imen. M.: Eksmo, 2006. $544 \mathrm{~s}$.

13. Yanin V.L. Ya poslal tebe berestu. M.: Izd-vo MGU, 1965. $192 \mathrm{s.}$

14. Zubenko Yu.S. Arkheologicheskaya nakhodka kak spetsificheskii vid kul'turnoi tsennosti: problema pravovogo opredeleniya // Filosofiya i kul'tura. 2012. № 10. S. 70-75. 